\title{
LOS AÑOS SIN REY. IMAGINARIOS ARISTOCRÁTICOS DURANTE LA SEGUNDA REPÚBLICA Y EL PRIMER FRANQUISMO (1931-1950) (1)
}

\author{
MIGUEL ARTOLA BLANCO \\ Universidad Carlos III de Madrid \\ martola@ing.uc3m.com
}

(Recepción: 15/05/2015; Revisión: 13/10/2015; Aceptación: 28/12/2015; Publicación: 02/12/2016)

1. UN MUNDO TRASTORNADO.-2. El IDEAL ARISTOCRÁTICO.-3. LA GÉNESIS DE UN PROYECTO CORPORATIVISTA. -4 . CONCLUSIONES. -5 . BIBLIOGRAFÍA

\section{RESUMEN}

Desde la caída de la monarquía en 1931 y hasta finales de la década de 1940, la aristocracia española participó de manera activa en los círculos monárquicos que aspiraban a restaurar a los Borbones en el trono. Como parte de esta acción política, la nobleza articuló un programa coherente con sus esencias como grupo de estatus que aspiraba a preservar el viejo orden liberal, salvaguardar a las élites ante el advenimiento de la sociedad de masas y hacer frente al doble envite de la democracia y la «demagogia social». Sin embargo, el proyecto aristocrático fue más allá de una simple fórmula contrarrevolucionaria, por cuanto buscó en el corporativismo la solución perfecta para poner en armonía a los actores en conflicto.

Palabras clave: Aristocracia; corporativismo; franquismo; monarquía.

(1) Este trabajo ha sido realizado en el marco del proyecto HAR2012-32713 del Plan Nacional de I+D+i. Agradezco los comentarios de Hugo García, José Miguel Hernández Barral y los dos evaluadores anónimos. La responsabilidad de posibles errores es únicamente mía. 


\title{
THE ARISTOCRATIC IMAGINARY DURING THE SECOND REPUBLIC AND EARLY FRANCOISM (1931-1950)
}

\begin{abstract}
Since the fall of the monarchy in 1931 and until the late 1940s, the Spanish aristocracy actively participated in monarchist circles that sought to restore the Bourbon dynasty on the throne. As part of this policy, the nobility articulated a coherent program with their nature as a status group, which sought to preserve the old liberal order, safeguard elites versus mass society and eliminate the double menace of democracy and «social demagogy». However, aristocratic politics went beyond a simple counter revolutionary formula and saw in corporatism a perfect solution to bring harmony among social actors.
\end{abstract}

Keywords: Aristocracy; corporatism; Francoism; monarchy.

$$
* \quad * \quad *
$$

Las últimas investigaciones históricas han coincidido en situar a la aristocracia como un actor que se mantuvo cohesionado en la época contemporánea gracias a preservar su estatus distinguido, un modelo particular de economía rentista y una identidad común que unía sus trayectorias familiares a los hitos de la historia de España (2). En cambio, a la hora de ponderar su impronta política, los debates han sido menos concluyentes. Mientras que en la década de 1960 y 70, Tuñón de Lara argumentaba que la fusión entre la aristocracia y la alta burguesía en un «bloque de poder» constituía la clave interpretativa del régimen de la Restauración, durante las últimas décadas varios historiadores han rechazado de plano esta interpretación en aras de defender la autonomía de las élites políticas (3). Esta nueva interpretación no ha ido en detrimento de que los investigadores hayan profundizado en el papel de la nobleza, bien como caciques locales, diputados en el Congreso o integrantes de la Corte (4). Si a estas facetas añadimos otras que aún no han sido exploradas con suficiente atención, entre ellas su destacado papel en las altas esferas del servicio diplomático y del Ejército, es razonable concluir que la nobleza fue un actor político relevante atendiendo tanto a su peso numérico, pero también por su apoyo incondicional a la Monarquía.

Este artículo busca explorar una faceta menos conocida de su historia, estudiando los proyectos e imaginarios políticos que articuló la aristocracia durante las dos décadas que siguen a la caída de Alfonso XIII. La aristocracia, tal como

(2) Artola Blanco (2014, 2015); Hernández Barral (2014); Sánchez Marroyo (2014).

(3) CABRERA y Rey Reguillo (2002); TuÑón de LARA $(1967,1981)$.

(4) Su peso en el Parlamento y la vida política local en Almansa Pérez (2005); GómezNavarro, Rey Reguillo, y Moreno Luzón (1998); González Cuevas (2003a); V arela OrteGA (2001). 
han señalado otros historiadores, era un concepto especialmente polifacético a principios del siglo Xx y así será entendido a lo largo de estas páginas (5). En un sentido básico apelaba a la nobleza, un actor que en el ámbito político fue generalmente presentado en términos negativos, es decir, como un grupo privilegiado que no cumplía función alguna y que vivía a costa de las rentas. Junto con esta vertiente, apareció otra definición de la aristocracia que la describía como un tipo ideal de élite que servía de freno a las masas y la democracia, pero que no solía incluir a la nobleza. Esta última definición remitía a las esencias del elitismo, en particular a los postulados de autores muy diversos de la esfera internacional (Mosca, Pareto, Spengler o Muret) y nacional (Ortega o Maeztu), que coincidían en señalar como naturales la desigualdad de atributos entre personas y que consideraba inevitable el dominio de una minoría con cualidades superiores -la élite- sobre la mayoría (6).

El objetivo de este trabajo es combinar estas dos tradiciones para demostrar cómo la nobleza artículo un proyecto político que tenía un carácter netamente elitista. Por una parte, se recuperará el interés por la nobleza como grupo de estatus y se profundizará en la visión que tenían sus integrantes sobre el rol político que debían cumplir en la sociedad contemporánea. Por otra parte, también se hará referencia a la relación de la nobleza con otras élites para insistir en cómo los nobles se identificaban con el concepto de aristocracia hasta el punto considerar ambos conceptos intercambiables y, en consecuencia, defendieron el «gobierno de los mejores». La perspectiva que se adopta es por tanto novedosa porque no trata la relación entre la nobleza y diferentes corrientes políticas (el fascismo, el maurismo o el nacionalismo conservador), sino que busca rastrear la esencia de su proyecto como grupo, a pesar de que este fue difuso, inconsistente $\mathrm{y}$, en último término, abocado al fracaso.

En términos académicos, un ejercicio de esta naturaleza resulta atípico por dos razones. Primero, porque la mayoría de estudios sobre la nobleza refieren a su momento de apogeo y, por tanto, tratan cuando nuestros protagonistas estaban integrados dentro del establishment y no veían necesidad de pensar en un nuevo horizonte político. En cambio, al elegir un periodo posterior, en el que la nobleza experimenta un proceso acelerado de declive y ve su posición amenazada desde distintos flancos, resulta más fácil encontrar un sustrato común de ideas que hasta entonces no resultaban tan evidentes. En segundo lugar, es palpable que entre los investigadores actuales resulta poco habitual relacionar un actor social con una corriente política, toda vez que parecería una suerte de reivindicación del estructuralismo marxista, en particular, de la vinculación entre clase social e intereses objetivos (7). El propósito de este artículo es más

(5) González Cuevas (2008); Mina Apat (2002).

(6) Mosca (1896); Pareto (1916); Spengler (1926); Ortega y Gasset (1930); Muret

(7) Una muestra de estos debates en Babiano Mora (2012) y CABrera Acosta (2001). 
sencillo. Simplemente se parte de la hipótesis de entender una serie de proyectos no como un esfuerzo individual o la expresión de una corriente política organizada, sino como el resultado de un estado de opinión compartido por un grupo de estatus. No se pretende afirmar que todos los nobles en España simpatizaran con esta visión política y desde luego no es anecdótico que algunos aristócratas se identificaran con opciones radicalmente opuestas (por ejemplo, con el anarcosindicalismo o el falangismo) (8). Sin embargo, como habrá ocasión de ver, hay razones para pensar que el deslizamiento hacia opciones contrarias a la monarquía fueron entendidas como una traición al grupo, mientras que el proyecto que presentaré sí aspiró a ser representativo de todo el estamento nobiliario. Así, la defensa de estos ideales ante la opinión pública fue realizada por los portavoces más autorizados de nobleza, es decir, por titulados, muchas veces con grandeza, que contaban con el respaldo directo de familias con un amplio capital económico, social y cultural. Además, dichas propuestas fueron acogidas con naturalidad en la asociación de la nobleza española -la Diputación de la Grandeza- a pesar de que esta declarase ser apolítica por naturaleza. Por último, este programa se expresó de tal manera que naturalizaba y reivindicaba el ethos aristocrático en el mundo contemporáneo.

Esta perspectiva se ve reforzada si se tiene en cuenta las actitudes que siguieron sus pares en Europa durante las décadas que discurren entre la crisis del liberalismo clásico y el estallido de la Segunda Guerra Mundial. Dentro de un contexto general de pérdida de hegemonía social, se produjo un renovado interés por la vida política entre las élites nobiliarias, que se orientaron hacia la derecha, bien hacia proyectos que aspiraban a mantener el viejo orden conservador o defendiendo una solución autoritaria (9). En Gran Bretaña, el punto de inicio de una política distintivamente aristocrática se expresó con la oposición de los lores a la reforma fiscal de Lloyd George, pero continuó a partir 1909 en torno al programa defendido por los tories die-hards que veían con gran alarma el avance de la democracia, el fortalecimiento del socialismo y la pérdida de la preeminencia imperial (10). Años más tarde, muchos de ellos simpatizaron por momentos con los fascistas de Mosley y, a título individual, algunos incluso llegaron a propugnar en 1940 por establecer una paz negociada con la Alemania nazi (11). En Francia, la tradicional división de las fuerzas monárquicas entre diversas corrientes (tradicionalista, orleanista y bonapartista) tuvo también su reflejo entre las familias nobles, aunque ello no impidió que durante el periodo

(8) El marqués de Vinent simpatizó con las corrientes más moderadas del anarcosindicalismo. Por el contrario, el conde de Foxá, el marqués de la Eliseda y muchos hijos de nobles estuvieron próximos al falangismo. Alfonso García (1998); GonZÁLEZ CueVAS (1996) y URQUiJO (1973).

(9) Cannadine (1999); Wasson (2006).

(10) PhILLIPS (1979).

(11) URbACH (2007). 
de entreguerras hubiera un apoyo continuado a Action Française (12). Por último, en Alemania, la nobleza también vio que su estatus social y su relación con el Estado quedaron en entredicho durante la república de Weimar. Su apoyo a las corrientes monárquicas, o más tarde al nazismo, debe entenderse como parte de un programa más amplio que aspiraba a acabar con el desorden y degeneración moral que atenazaba a la sociedad, impusiese el dominio de las élites (el llamado neoaristokratismus) y construyese un sistema corporativista (13).

El reto en el caso español radica en ir más allá de los vaivenes de la coyuntura, en particular sobrepasar el umbral de la Guerra Civil, para tomar en cuenta las actitudes de las familias nobles durante esta época y desentrañar la naturaleza de un programa que aspiraba a construir (o preservar) un sistema político que garantizase el dominio de las minorías en un contexto de fuerte movilización de las masas. El artículo discurre de la siguiente manera. En el primer apartado proporciono una visión general sobre la nobleza en este periodo y apunto a los principales retos que ya han sido identificados por los historiadores. Después, analizo la creación entre la aristocracia de un estado de opinión anti-democrático y elitista, mostrando las similitudes y diferencias con otros pensadores contrarrevolucionarios de la época. Como continuación, expongo de forma pormenorizada el horizonte de restauración monárquica y el modelo de Estado corporativo que propusieron tres nobles (el marqués de la Eliseda, el conde de Campo Alange y el vizconde de Eza). Por último, en las conclusiones hago una recapitulación de los principales puntos.

\section{UN MUNDO TRASTORNADO}

La caída de Alfonso XIII supuso para la aristocracia el inicio de un periodo de crisis e incertidumbre que no se dio por terminada con la Guerra Civil, sino que perduró con menor intensidad hasta finales de la década de 1940. La democracia republicana y la dictadura franquista, a pesar de situarse en las antípodas políticas, constituyen dos regímenes en los que el grupo experimentó una notable pérdida de poder, creciente aislamiento y multiplicación de retos. Dada la vinculación intrínseca entre la nobleza y la Corona, resultaba inevitable que hubiera una gran incertidumbre ante la falta de su referente por excelencia (el rey), pero también porque todos los actores políticos que buscaban marcar distancias con el pasado monárquico tomaron a la nobleza como su enemiga.

Empezando por su estatus legal, el gobierno provisional de la República fue tajante en querer borrar su impronta en la esfera pública, pues no solo prohibió

(12) BRAVARD (2013); MALINOWSKI (2007).

(13) BARANOWSKI (1995); Glassheim (2005); CONZE (2007); D' Almeida (2008). 
el reconocimiento de los títulos nobiliarios, sino que también negó que sus anteriores poseedores pudieran utilizarlos en documentos civiles. Era una política que negaba la misma existencia del grupo -en 1932 era habitual referirse a la «desaparecida grandeza»- y que fue un paso más allá de la aplicada en dos regímenes republicanos de referencia, Francia y Alemania, donde el Estado sí reconoció el uso de títulos en los documentos civiles en sustitución o acompañando al nombre (14). El problema no se dio por finalizado con el desmantelamiento de la política republicana tras la Guerra Civil, dado que Franco mantuvo un cómodo vacío legal hasta que en 1948 optó por reconocer de nuevo los títulos. Esta indefinición fue acompañada de una retórica discursiva que situaba a la aristocracia como el arquetipo de una casta parasitaria que retrasaba el desarrollo del país y que conspiraba entre bastidores para preservar sus privilegios. Es bien conocido tanto que Azaña denunció a los grandes de España por «defender»y «sostener» al anterior régimen monárquico, pero también las escasas simpatías que despertaba en Franco esos «parásitos», que «nada hacían por el prestigio» de Alfonso XIII (15). Estos discursos tuvieron su natural continuación en diversas políticas y reformas sociales que buscaron limitar el poder económico de la nobleza y de otras élites tradicionales. La reforma agraria de 1932, que contemplaba la expropiación de los grandes de España, puede verse como el ejemplo más extremo de esta línea política, pero tampoco debe olvidarse el impacto duradero que tuvo entre las familias con grandes patrimonios la regulación de los arrendamientos rústicos y de los alquileres urbanos emprendida por el régimen franquista (16).

En este contexto no es de extrañar que las formas de movilización de la nobleza discurrieran por nuevos cauces. Durante la Restauración los nobles que participaban en política lo hicieron a título individual, dentro de las redes clientelares de los partidos liberal y conservador, por lo que cualquier iniciativa que clamaba por unir a la nobleza como un estamento unificado, como llegó a proponer el conde de Torres Cabrera a través del Centro de Acción Nobiliaria, fue vista como innecesaria o excéntrica (17). En cambio, a partir de 1931, la acción corporativa o en términos de clase comenzó a ser entendida como un requisito imprescindible (18). La gran mayoría se integró en Renovación Española, un partido contrarrevolucionario de corte monárquico, pero también muchos sostuvieron las tramas golpistas contra la República (19). Unos años más tarde, al

(14) MACKNIGHT (2012): 17-20.

(15) Azaña en Diario de sesiones de las Cortes Constituyentes de la República española, número 232, p. 8675. La opinión del dictador, en Franco SALGADO ARAujo (1976): 68-70, citado por GonZÁLEZ CuEvas (2008).

(16) Artola Blanco (2012, 2013); Malefakis (1976); Robledo (2012).

(17) GonZÁLEZ Cuevas (1993): 225-267.

(18) Alcalá-Galiano (1934): 12.

(19) Gil Pecharromán (1994); González Calleja (2011); GonzÁlez Cuevas (1998): 81-121. 
estallar la Guerra Civil, todas las contradicciones del periodo (el sentimiento anti-aristocrático entre las izquierdas, la movilización unitaria de la nobleza, etc.) se expresaron en su forma más cruda. Durante la contienda murieron 177 nobles, la inmensa mayoría víctimas de la represión en la retaguardia republicana (20). Para comprender la magnitud de estas cifras cabe señalar que suponían cerca de un diez por ciento del estamento nobiliario en aquel momento (1875 personas) y que el número de bajas quedó atenuado debido a que la contienda comenzó en verano, cuando muchos aristócratas ya habían abandonado Madrid (21). Por su parte, las familias nobles apoyaron incondicionalmente al bando nacional, proporcionando numerosos voluntarios entre sus generaciones más jóvenes o realizando importantes donaciones para el esfuerzo de gue$\operatorname{rra}(22)$.

El final de la contienda abrió una nueva etapa para la nobleza, pues, gracias a la victoria franquista, la República y todas las reformas sociales que la habían acompañado quedaron enterradas para siempre. Además, debido al temor que generaba el pasado republicano, muchas familias nobles otorgaron una legitimidad adicional a la dictadura franquista, tal como señalaba una periodista americana:

La aristocracia española [. . . ] ha quedado profundamente marcada por la Guerra Civil, especialmente porque ha promovido un profundo y genuino temor al comunismo. Están determinados a que los rojos nunca vuelvan a tener la iniciativa, aunque nunca se han parado a pensar en qué provoca el comunismo. Simplemente saben que no les gustan sus efectos (23).

Sin embargo, bien fuese por la amenaza que suponía la revolución nacional que quería poner en práctica Falange o por los recelos que despertaba la consolidación de Franco como Caudillo de España, lo cierto es que muchos aristócratas guardaron ciertas reservas con respecto al régimen y apoyaron la causa monárquica en favor de la vuelta al trono de Don Juan. Queda aún por escribir un estudio detallado sobre la oposición monárquica al franquismo, en la cual sería conveniente que los historiadores fuesen más allá de la lucha personal que entablaron Franco y Don Juan (24). Hasta el momento, todos los indicios apuntan a que la aristocracia ocupó un papel muy destacado entre los círculos del interior, tanto en términos organizativos (colecta de fondos, organización de reuniones y difusión de publicaciones) y, sobre todo, proporcionando un apoyo moral y simbólico al pretendiente al trono.

(20) Bullón de Mendoza (2000): 99.

(21) El número de nobles según MORENo MORRISON (1932)

(22) San Juan de Piedras Albas (1945); Seidman (2012): 150-156.

(23) MoAts (1945): 49. Traducido del inglés.

(24) Relatos generales en Anson (1994); Barba Prieto (2001); Collado Seidel (2007); TUSELL (1977) 


\section{EL IDEAL ARISTOCRÁTICO}

Tomando en cuenta estos antecedentes, resulta fácil comprender por qué la aristocracia mantuvo un compromiso inquebrantable con la restauración monárquica. Lo que no resulta tan evidente es que sus aspiraciones fuesen más complejas de lo que en general se ha reconocido, pues en lugar de quedar reducidos a un papel pasivo como servidores leales de los Borbones o como unos ultra-conservadores que añoraban las esencias del sistema constitucional de 1876 , lo cierto es que durante estos años muchos nobles mostraron una notable inquietud política que se expresó a través de múltiples canales. Asimismo, resulta muy significativo que, aunque estos autores no articularan un corpus teórico unificado, ni tampoco parece que hicieran un trabajo colectivo de elaboración, sí compartieron una serie de imaginarios, representaciones y lenguajes comunes. A diferencia de muchas otras personalidades conservadores de la época, sus propuestas deben ser valoradas por su consistencia en el tiempo -al mantener un hilo de continuidad entre el periodo anterior y posterior a la guerray por superar el estadio de una reflexión intelectual, pues sus escritos muchas veces fueron entendidos como el preludio de un plan de acción.

Las referencias que nutrían el proyecto político de la nobleza eran claras. Su esencia estaba ligada al reconocimiento de la monarquía como fórmula política óptima, la defensa de los principios conservadores frente a los peligros del mundo moderno, una visión dicotómica de la sociedad que separaba a las élites de las masas -atribuyendo a las primeras su superioridad y autoridad- y la apuesta por el corporativismo como solución para integrar en armonía a todas las clases sociales. En esa época de incertidumbres, la nobleza no era la única en enarbolar estos principios y existían notables paralelismos con el programa defendido durante los años de la República por varios intelectuales de derechas encabezados por Ramiro de Maeztu en Acción Española. El vínculo entre ambos grupos no era fortuito dado que, tal como ha señalado González Cuevas, la nobleza prestó un soporte activo a esta publicación como atestigua su participación como autores, canalizando su apoyo financiero en diversas colectas y reforzando la difusión como lectores asiduos (25). En consecuencia, la aristocracia española conocía bien los escritos de estos intelectuales contrarrevolucionarios y comulgaba con muchos de sus principios, si bien ello no impidió que desarrollara una línea de pensamiento propio. Su experiencia como grupo le llevó a coincidir en importantes puntos en común, como su rechazo a la democracia, la lucha contra la República o su miedo a las masas, pero también es fácil encontrar diferencias notables, como la relación entre tradición y modernidad, el modelo de monarquía imaginada, el ideal que debía conducir a la formación de las élites o la conveniencia de imitar sistemas extranjeros. Al ilustrar algunos de estos aspectos, el proyecto de la nobleza resultará más nítido.

(25) GonZÁlez Cuevas (1998): 146-156. 
No hay duda de que los intelectuales de Acción Española y la nobleza confluían en rechazar la democracia, la pérdida de preeminencia por parte de las élites y la inevitable tendencia niveladora que producía el avance de las masas. Sin embargo, si los primeros venían denunciando esta serie de fenómenos desde la crisis de la Restauración, los segundos solo habían tomado conciencia plena de estos problemas a partir de 1931. Las memorias de muchas personalidades aristocráticas dan cuenta de la persistencia de un estado de opinión distendido entre sus filas hasta los compases finales del reinado de Alfonso XIII, por lo que de manera inevitable solo podía explicarse el repentino final de la monarquía en razón de una desdichada concatenación de factores adversos, como la acción de los conspiradores republicanos, la ineptitud de los dirigentes políticos y el retraimiento de las clases conservadoras en las elecciones de 1931 (26). Será solo en los meses siguientes, en un contexto en que muchos nobles tomen la vía de un exilio voluntario en Francia, cuando se manifieste en todas sus facetas un estado de opinión contrario a la modernidad. El marqués viudo de Camarasa fue el primero en iniciar las críticas, cuando apenas dos días después de la proclamación de la República publicó un breve pasquín que señalaba como causa última del desastre la aprobación del sufragio universal en 1890, por lo que al final había resultado inevitable que «el rebaño» se impusiera al «pastor» (27). El conde de los Villares fue más radical al señalar que, junto con la «decidida intervención de las sociedades secretas», había percibido una profunda degeneración moral de la sociedad española en los últimos años. Recordaba cómo en una de sus visitas a la universidad le sorprendió encontrar que nadie guardara el debido respeto a los catedráticos y que entre las estudiantes hubiera alguna señorita que «escuchaba con delectación los piropos de sus compañeros». De igual manera, el conde cargaba las tintas en las actitudes que había encontrado entre sus iguales, en particular entre unas «clases altas» que habían situado «el dinero» por encima del «honor» (28). Por último, el vizconde de Eza fue tajante en criticar el bajo nivel cultural de las democracias contemporáneas, que solo leen «o le interesan los divorcios o los cines, los sitios de baile y los procesos policiacos», hasta el punto que parecía imponerse una «especie de ley Gresham por la cual toda buena y bien meditada opinión es constantemente expulsada por lo que es precipitado, impulsivo y mal conducido» (29).

Como contrapunto a las tendencias que auguraban al triunfo de la mediocridad, resultaba natural defender que las élites -en particular la aristocracia- actuasen como garantes del orden social. La defensa del elitismo continuaba una larga tradición en España que clamaba por la existencia de minorías selectas para frenar cualquier veleidad democrática o tendencia niveladora (30). Esta

(26) Alcalá Galiano (1933); Vilallonga (2001); Villavieja (1938): 114-115.

(27) CAMARASA (1931): 8

(28) Villares (1932): 67 y 129.

(29) EZA (1945): 16

(30) Mina Apat (2002); SierRa (2010): 329-330. 
línea de pensamiento podía ser atractiva para la nobleza, pero sin embargo resultaba difícil de asumir al completo por cuanto expresaba también muchas de las críticas vertidas contra su grupo por parte de los autores regeneracionistas. Dos intelectuales tan destacados de esta corriente, como fueron Ortega y Maeztu, enfatizaron de forma recurrente las diferencias entre aristocracia y nobleza: la primera recogía el ideal clásico de la selección de los mejores, mientras que la segunda era vista como una casta cerrada, ociosa y parasitaria que poco podía aportar a la modernización de España (31).

La nobleza, al encontrarse huérfana en términos políticos y viendo su posición amenazada con la nueva legislación republicana, realizó una defensa incondicional de sus esencias, pero también comenzó a elaborar un proyecto elitista que potencialmente uniese a todas las clases conservadoras. Los escritos de los nobles en esta época se caracterizan ante todo por reclamar la fortaleza de las élites frente a las tendencias igualitarias de la República o la demagogia social de Falange. En algunos casos, su defensa se hizo en un sentido restrictivo y corporativo, de forma que solo se ensalzaban las virtudes de la nobleza en el mundo contemporáneo. Un artículo anónimo titulado «El prejuicio nobiliario» publicado en La Época -el viejo periódico conservador dirigido por el marqués de Valdeiglesias- resumía el núcleo de este tipo de argumentos. Partiendo del principio inevitable de que «la jerarquía se impone entre los hombres en una u otra forma», reclamaba los valores propios del ideal nobiliario, tales como la herencia, la tradición y la educación en familia, por cuanto la experiencia demostraba que «el abolengo influye en la aptitud y la sostiene, obliga a mirar el cumplimiento del deber con tal elevación, que ha de supeditársele el bienestar» (32).

Fue más frecuente que los aristócratas abogaran por un proyecto más ambicioso que reclamaba la defensa de las élites, y no solo de la nobleza, como forma de incluir a la mejor selección de los hombres de la política, los negocios, las artes y las ciencias. El duque de Alba, al leer su discurso de investidura como decano presidente de la Diputación de la Grandeza, fue tajante en este sentido. Para él resultaba claro que «siempre hicieron falta Aristocracia y Clase directoras [...] No digo Aristocracia exclusivamente de sangre sino una Selectocracia, porque todo el país que la tenga será, en general, mejor gobernado» (33). El vizconde de Eza dedicó también una parte importante de sus escritos a esta cuestión, en particular en un libro cuyo título hablaba por sí solo: Vivero de selectócratas (La función de las clases directoras en las sociedades modernas) (34). Eza sin duda fue el noble que más lejos llevó el planteamiento de superar las fronteras de su grupo, al enfatizar que la cuestión no estribaba en resucitar

(31) GonZÁlez Cuevas (2003b, 2008)

(32) «El prejuicio nobiliario», La Época, 24 de diciembre de 1932.

(33) Alba (1943b): 8

(34) EZA (1940). 
«anacronismos [como] valorar los hombres por sus apellidos nobiliarios», sino el de formar a una clase directora a partir de la aristocracia de la alcurnia, la fortuna, la tecnocracia, escritores y literatos (35). Por último, incluso una personalidad tan disconforme con la dictadura franquista y apegada a las garantías constitucionales como fue el duque de Maura, no dudó en reclamar una «minoría selecta» que movilizase a las «masas y enardecerlas hasta el punto de conseguir de ellas una colaboración efectiva, constante, paciente y duradera» (36).

El punto más importante de estos proyectos no era tanto ensalzar las virtudes del gobierno de los pocos como insistir, de manera más o menos explícita, en que las élites tomaran elementos del bagaje nobiliario. Una de las virtudes que reclamaba para sí misma la nobleza era su ligazón con la historia, pues dado su profundo conocimiento de la genealogía o por la vinculación de sus linajes con el servicio a la Monarquía, parecían encarnar la «ficción de la continuidad» con el pasado (37). Siguiendo estas premisas, muchos nobles presentaron sus argumentos siguiendo un enfoque historicista, como si su experiencia permitiese deducir enormes paralelismos entre los conflictos del momento y aquellos que pudieron plantearse durante la Antigüedad clásica o a la Edad Media. En 1935 el conde de Ribadavia situaba la reforma agraria republicana como parte de una tendencia recurrente a favor del reparto de las tierras por parte de demagogos y populistas -desde Solón y Julio César hasta los bolcheviquesque terminaban siempre fracasando, porque ser propietario no era una condición alcanzable más que a unos pocos y, por tanto, el acceso de todos los hombres a la riqueza resultaba «imposible» (38). El duque de Alba fue igual de tajante en el discurso que pronunció al entrar en la Real Academia: «La historia nos demuestra la necesidad de aristocracias para gobernar. [...] Estas crean, la plebe destruye y el triunfo del número ha marcado siempre el fin de las civilizaciones. [...] Roma, Venecia, Inglaterra son buenos ejemplos» (39).

Resultó igual de frecuente presentar una visión idílica del Antiguo Régimen, hasta el punto de ver en la sociedad estamental un contrapunto a la lucha de clases que atenaza al mundo contemporáneo. El Premio Cervantes que cada año convocaba la Diputación de la Grandeza al mejor estudio histórico constituye un excelente botón de muestra de estas preocupaciones, por cuanto su consejo fijaba de antemano un tema predilecto (40). En 1947 se convocaban a concurso los estudios sobre «Las clases sociales españolas durante la primera mitad del siglo XVII y su cordial convivencia demostrada con textos cervantinos», mientras que en otro año el tema elegido fue las «Relaciones de la nobleza con sus pueblos y plan de una codificación de las Ordenanzas dadas por los

(35) EZA (1940): 9 y 44.

(36) MAURA GAMAZO (1934): 248.

(37) Bourdieu (2007); Saint Martin (1993): 385 y ss.

(38) Rivadabia (1935): 4-6.

(39) Alba (1943a): 27.

(40) Sobre el premio Cervantes, HeRnÁndez BARRAL (2014): 224. 
Señores a sus vasallos» (41). A colación de este último premio, el duque de Alba publicó una recopilación de las fuentes conservadas en su archivo, incluyendo un prólogo donde dejaba constancia del contraste entre la «afabilidad» y «diálogo» que imperaban en el pasado con respecto a un presente en el que: «Se pretende invertir todos los valores y parecen amenazados de desquiciamiento el equilibrio mantenido por la sociedad durante siglos, la tranquilidad de los propietarios en el disfrute de las rentas y el sustento de los productores de ellas con su penosa labor» (42).

Como colofón se acudía a Oswald Spengler como fuente de autoridad, en particular a su obra magna La decadencia de Occidente, pero también a otros trabajos posteriores de indiscutible signo conservador (43). El atractivo de Spengler radicaba por una parte en su denuncia del impulso destructivo de las masas, la insistencia en las virtudes de la nobleza y la defensa del gobierno aristocrático. También era muy sugerente su visión sobre la evolución de las culturas, que entendía como sociedades más prósperas aquellas basadas en la agricultura y la propiedad, en contraposición a la degeneración intrínseca al comercio y las finanzas. Siguiendo estas premisas surgía la segunda y más importante virtud de la nobleza: su vinculación con este ideal primitivo y paternalista de la propiedad. La nobleza podía entonces vanagloriarse de que su fortuna seguía anclada en los bienes inmuebles -fincas rústicas y urbanas-, que cuidaba con celo la conservación del patrimonio entre generaciones y que se alejaba del ideal del especulador, por cuanto no exigía más que una «renta mezquina (del 2 al 3 por ciento)» (44). El régimen aristocrático iba más allá de su significado clásico como «gobierno de los mejores», para devenir en un sistema en donde «la jerarquía política corresponderá, poco más o menos, a la posición social». La consecuencia natural sería que el gobierno quedaría en manos de «personas distinguidas, honorables y desprendidas que estiman mucho más los honores y la gloria que el dinero que ya tienen» (45).

En las antípodas, igual que se miraba con recelos la fuerza perturbadora de las masas y se criticaban los proyectos redistributivos, la democracia aparecía como el peor de los sistemas de gobierno: «El ideal democrático, en el verdadero sentido de la palabra, nunca fue, ni en conjunto ni en detalle, sino un resu-

(41) El primer premio en Diputación permanente y Consejo de la Grandeza de España: Memoria correspondiente a 1947. Archivo de la Casa de Alba (ACA), Fondo de Don Jacobo, Caja 4. El segundo premio en AlbA (1928): 3.

(42) Alba (1928): 5.

(43) Spengler (1926). Le citan Alba (1943a); Alcalá-Galiano (1928); Eza (1943); RiVADABIA (1935): 18 y 24. Conviene señalar que este autor no solo despertó el interés de la aristocracia española, pues en Alemania el mismo Spengler fue invitado en 1924 a la asamblea anual de la nobleza alemana para dar una conferencia sobre el rol de las clases dirigentes en las sociedades contemporáneas. STUART Hughes (1952): 114.

(44) RivadABia (1935b): 25.

(45) RivadABIA (1935b): 26. 
men de groseros errores. La voluntad, la decisión, la iniciativa, salen de un grupo reducido; luego las mayorías prestan su asentimiento o su aceptación» (46).

Declaraciones de este tipo deben leerse con cierta cautela pues no implicaban un rechazo pleno a la tradición liberal ni tampoco del parlamentarismo, sino que eran una manera de insistir en que el sistema de gobierno quedara impregnado de valores elitistas. Para los contemporáneos los ejemplos resultaban claros cuando contemplaban el panorama internacional. Casi todos los nobles coincidían en ensalzar a Inglaterra como modelo de convivencia perfecta entre las élites, la clase política y el pueblo, mientras que Francia era denostada como la tierra de «los idólatras de Marat y los secuaces de Robespierre», donde habían germinado esos «absurdos derechos del hombre» $\mathrm{y}$ «dogmas igualitarios» que el tiempo había demostrado incompatibles con el temperamento español (47). En conclusión, una voz tan autorizada como la del duque de Alba -embajador en Londres desde 1937 hasta 1945- insistía en el ideal de un «sistema parlamentario [que] está imbuido por un espíritu aristocrático», añadiendo que, en su parecer, la democracia no existía ni en Inglaterra ni en Estados Unidos: «Ambos están manejados, cada uno en su modalidad, por selecciones de clases dirigentes» (48).

\section{LA GÉNESIS DE UN PROYECTO CORPORATIVISTA}

Si en las primeras fases de este periodo crisis y aislamiento los portavoces de la nobleza se esforzaron en legitimar su posición social y defender en un sentido abstracto las virtudes del ideal aristocrático, con el tiempo fueron madurando sus ideas hasta llegar a nuevas fórmulas que permitiesen cerrar los conflictos de la época. En este tránsito, la Guerra Civil y la posterior instauración de la dictadura franquista constituyen el punto de inflexión decisivo por cuanto enterraron para siempre la amenaza más importante -la República-, pero también dejaron una profunda huella en la memoria colectiva del grupo debido a la virulencia del terror revolucionario. La década de 1940 situó también en un nuevo horizonte la posible restauración de la monarquía. Entre los grupos más vinculados al entorno del conde de Barcelona se extendió un estado de ánimo optimista que consideraba inminente la vuelta al trono de Don Juan gracias al apoyo de las potencias aliadas, hasta el punto que en el verano de 1945 se llegó a debatir sobre la formación de un gobierno provisional (49).

(46) Alba (1943a): 24.

(47) Diatribas anti-francesas en AlCALÁ-GaLIANo (1934): 23-26.

(48) Alba (1943a); Avilés FarRé (1996): 167.

(49) ANSON (1994): 236-237 refiere a una propuesta de gobierno provisional que incluía a figuras moderadas del exilio (Salvador de Madariaga), militares descontentos (el general Kindelán), intelectuales (Marañón) y financieros de reconocido prestigio (Garnica, presidente de Banesto). 
Otros colectivos monárquicos, entre los que se encontraban no pocos aristócratas, prefirieron insertarse en las estructuras del Movimiento con la perspectiva de llegar a un entendimiento con Franco, sin por ello renunciar al horizonte de una restauración (50).

Estas diferencias crearon el clima perfecto para que durante unos pocos años hubiera una efervescencia de debates en los círculos monárquicos en la forma de propuestas, borradores, proyectos de reforma política o simples esbozos para restaurar la monarquía. Para el historiador actual a menudo resulta difícil identificar a los autores individuales de estos escritos, pues, ante la amenaza de ser vigilados o denunciados por las autoridades, resultó frecuente el recurso al anónimo o a transmitir las consignas por vía oral. Por ejemplo, en una de las actas del consejo de la Diputación de la Grandeza se dejaba constancia que

En cuanto al encargo dado por S. A. el Infante D. Alfonso de Orleans en carta dirigida al Sr. Duque de Montellano fecha 8 de julio de 1945 sobre la actitud a seguir por los Miembros de la Nobleza respecto a Franco y Falange, se acuerda hacerlo llegar a los componentes de la Clase verbalmente y no por escrito por parecer así más conveniente dadas las actuales circunstancias (51).

Pero ni el anonimato ni el diferente grado de inserción en el régimen franquista impidieron que la nobleza continuara formulando una línea política coherente con sus ideas anteriores a la par que identificaba nuevas amenazas. Uno de las novedades de la posguerra fue la ferviente crítica de la intervención de los poderes públicos en la vida económica y social. Ante las pretensiones de las autoridades de crear empresas públicas, regular los arrendamientos o controlar los tipos de interés en el sistema financiero, comenzó a ser frecuente denunciar desde las filas aristócratas ese pretendido «socialismo de Estado» que encarnaba el proyecto falangista (52). El franquismo era censurado por haber secuestrado a la clase media con «ese monstruoso monopolio sindical», ahogado la iniciativa privada en la industria y la banca, subido los impuestos, aumentado la deuda pública y provocado la inflación (53). Ni en el fondo ni en la forma era una visión que tuviera en cuenta a las «masas», sino que enlazaba con el eterno problema de las élites y valores que debían dirigir un régimen político. El «megalómano régimen franquista» fue simple y llanamente identificado con esos

(50) Collado Seidel (2007): 124-125.

(51) Acta de la sesión ordinaria celebrada por el Consejo de la Diputación de la Grandeza de España en Madrid a 8 de enero de 1946, ACA, Fondo de Don Jacobo, caja 4.

(52) Situación política y económica de España y peligros nacional que entraña su perturbación, Real Academia de la Historia, Fondo Romanones, AR L98/133.

(53) A su excelencia el General Franco, Jefe del Estado Español. Madrid, Comité de Acción pro-Restauración de la Monarquía, 1949, copia de un escrito. ACA, fondo de Don Jacobo, caja 13. 
«advenedizos y nuevos ricos, carentes del concepto del verdadero "señorío", de la genuina calidad del caballero y señor» (54).

Durante estos años también se produjo un cambio notable en la forma de imaginar el sistema político ideal. Si durante la Segunda República los nobles habían cargado las tintas en denunciar los peligros que entrañaba el potencial triunfo de la democracia y de la sociedad de masas, en los cuarenta las preocupaciones fueron orientándose en buscar una fórmula política óptima que permitiese llegar a una paz duradera. El recurso a una dictadura personal como la de Franco se podía justificar como una solución temporal, que desde luego había sido necesaria en 1936 ante el pretendido avance del comunismo, pero que no tenía posibilidad de producir un sistema institucional estable. De igual manera, y como cabría esperar, la República era abiertamente rechazada, pues «aunque [fuese] representada por los hombres más moderados [...] se encontrará una gran resistencia del Ejército, de la Iglesia, de las clases capitalistas y de la burguesía media» (55). En cambio, la monarquía era imaginada como una institución alejada del conflicto de clases y de las divisiones marcadas por la Guerra Civil que eliminaría «las suspicacias y privilegios que, todavía hoy, dividen a los españoles en castas o en bandos antagónicos» (56).

La defensa de la monarquía como forma de Estado fue acompañada de una reivindicación del parlamentarismo contra las pretensiones autoritarias y personales de la dictadura de Franco, pero también como baluarte frente a la democracia. Se pretendía que hubiera un trasvase de poder a una asamblea representativa, pero también que las elecciones no se hicieran por medio del sufragio universal, pues ello solo podía conducir a la «demagogia [que] provee de armas a la cantidad y deja indefensa a la calidad» (57). Como resultado, algunos nobles reclamaron las viejas esencias del liberalismo más conservador en base a las siguientes líneas básicas: restaurar la Constitución de 1876, formar un ejecutivo de «hombres de gobierno, rígidos en mantener el orden social» y dictar una: «Ley electoral [que] no podrá basarse en la fórmula simplista de UN HOMBRE UN VOTO porque es una fórmula que conduce al predominio de las masas ignorantes y apasionadas. Debe establecerse el VOTO CUALITATIVO según sus títulos facultativos y su capacidad contributiva» (58).

Sin embargo, muchos otros se resistieron a supeditar su programa a una simple vuelta a las viejas fórmulas del liberalismo decimonónico y buscaron en el modelo corporativo la solución perfecta para los problemas de la época. El corporativismo, entendido como un proyecto institucional que contempla la

(54) A su excelencia el General Franco...

(55) [Panfleto sin título]. 30 de septiembre de 1946. ACA, fondo de Don Jacobo, caja 13.

(56) [Panfleto sin título]. 30 de septiembre de 1946. ACA, fondo de Don Jacobo, caja 13.

(57) MaURa Gamazo (1952): 65.

(58) Porque debe restaurarse la monarquía constitucional. Bases para esta restauración. 1944. Copia mecanografiada. ACA, Fondo de Don Jacobo, caja 13. Las mayúsculas en el original. 
inserción de las asociaciones civiles (sindicatos, gremios, cooperativas, cuerpos técnicos, etc. ) en las estructuras del Estado, había gozado de una auténtica edad de oro en la Europa de entreguerras (59). Si bien la heterogeneidad de los autores corporativistas impide situarles a izquierda o derecha, no hay duda del atractivo que tenía para la nobleza algunos elementos de este ideal, en particular, la defensa de la propiedad privada, la obligación de dotar de un código moral a los miembros de la comunidad frente a los peligros del individualismo y por clamar por una tercera vía entre capitalismo y socialismo. Si a ello añadimos que en España el corporativismo tuvo desde sus orígenes un indudable sesgo católico, conservador y nacionalista habida cuenta del sello personal que imprimieron sus impulsores (Ramiro de Maeztu, Aunós, Víctor Pradera, etc.), la conexión resulta más clara todavía (60).

Los proyectos corporativistas de la nobleza se diferencian de sus anteriores propuestas políticas al ir un paso más allá e imaginar un modelo de Estado que permitiría integrar a todas las clases sociales en armonía. Asimismo, adquieren un inconfundible sesgo totalizador al tomar las corporaciones como nexo de unión de todos los individuos como forma de ordenar las relaciones entre sociedad, política y economía. Las propuestas aristocráticas contienen también rasgos distintos a otras corrientes corporativas de la Europa de entreguerras, como manifiesta su reivindicación de la monarquía, la defensa del gobierno de las élites a través de un parlamento que reúna «a los mejores» y su inconfundible tono historicista que rescataba (o reinventaba) tradiciones del liberalismo decimonónico o del Antiguo Régimen. Por último, como se verá a continuación, también existían diferencias notables con los elementos corporativos que perfiló el régimen franquista, entre ellos la unión de trabajadores y empresarios en un sindicato único de productores o la representación en las Cortes de los municipios, los sindicatos y las familias (61).

Las líneas básicas de este proyecto aparecen en los escritos de tres nobles destacados en esta época: el marqués de la Eliseda, el conde de Campo Alange y el vizconde de Eza. La trayectoria política del primero de ellos ha sido analizada en detalle por González Cuevas (62). El marqués de la Eliseda, Francisco Moreno y Herrera, formaba parte de una de las familias terratenientes más importantes de Jerez de la Frontera. Durante los años 30 simpatizó abiertamente con el movimiento fascista y, como resultado de su amistad con Primo de Rivera, militó en Falange Española. Sin embargo, como bien señala González Cuevas, él no era un fascista convencido, sino a lo sumo un conservador que estaba en proceso de «fascistización». Eliseda se sintió profundamente atraído por el ímpetu contrarrevolucionario de este movimiento y por la defensa que hacía del

(59) SCHMitTER (1974).

(60) FERNÁNDEZ RiQuelme (2008).

(61) Sobre las Cortes franquistas, véase el reciente trabajo de GiMÉNEZ MARTínEZ (2012).

(62) GonZÁlez Cuevas (1996). 
corporativismo como medio para crear nuevos vínculos y obligaciones entre los individuos. Por el contrario, en otros aspectos el marqués manifestó un punto de vista alejado del fascismo y que, en cambio, era más próximo al ideal aristocrático. A lo largo de su vida, Eliseda hizo una defensa constante de la monarquía como garantía de la continuidad histórica y afirmó que la aristocracia constituía la clase directora «natural» frente a los peligros que entrañaba la demagogia o la plutocracia. En 1945 publicó la que sería su obra más conocida, Autoridad y Libertad, donde dedicaba sus últimas páginas a una serie de propuestas genéricas para establecer un sistema monárquico en el que el sufragio estaría restringido a los «cabeza de familia con independencia económica» y se formaría un Parlamento corporativo con representantes de las agrupaciones económicas, municipios, diputaciones, universidades, la nobleza, el Ejército y la Iglesia (63).

Al conde de Campo Alange, que no tuvo una vida política en activo destacada, se le puede atribuir una obra manuscrita de 1943 titulada Proyecto de un régimen liberal corporativo que se conserva en el archivo de la Casa de Alba (64). El texto tiene un especial valor porque su autor incluyó un amplio preámbulo que ligaba esta propuesta política con un ideal sobre las formas de jerarquización social. Campo Alange se situaba en la antítesis del régimen franquista, pues si este negaba las divisiones de clase en su definición de «productores», él consideraba inevitable que existieran tres clases sociales. El capital y el trabajo eran las dos clases básicas cuya existencia no podía entenderse por separado: «El esfuerzo es el factor básico social. De él brota la riqueza; de esta proviene el ahorro, y con ahorro se amasa capital. El trabajo y el capital son, pues, el punto de partida y el punto de llegada del esfuerzo material humano». Junto con ellos, la técnica, propia de las clases medias (abogados, ingenieros, arquitectos, etc. ), cumplía la función de reducir las tensiones sociales, actuando «a manera de un puente que facilita el paso de uno a otro». El conde aspiraba a establecer la armonía entre estas tres clases, al propugnar la creación de sus correspondientes corporaciones que fuesen «neutras» en términos políticos y religiosos. Pero además, haciendo honor de su vertiente liberal, admitía que existiesen agrupaciones dedicadas a la defensa de «ideales políticos», a condición de que evitasen la «representación de intereses». Después, los españoles elegirían concejales y diputados en las instituciones locales siguiendo estos cauces. La mitad de los cargos serían elegidos entre los candidatos de los partidos políticos y la otra mitad, dividida a su vez en tres tercios, representaría al capital, la técnica y

(63) ELISEDA (1945): 217-220.

(64) Ni la autoría ni la fecha de este manuscrito es evidente. El texto está escrito a máquina y no lleva firma, pero, como era habitual en la organización de los papeles personales del duque de Alba, su archivero o secretario añadió a lápiz la siguiente expresión para identificar al autor: «Del Conde de Campo de Alange (Velázquez 124). Enero 1943». Proyecto de un régimen liberal corporativo, ACA, Fondo de Don Jacobo, caja 13. 
el trabajo. Por último, se imitaría este sistema para elegir a los diputados del Parlamento por medio de sufragio indirecto.

El reconocimiento de estos derechos era compatible con el más firme rechazo de las formas de movilización de la sociedad de masas. Campo Alange fue muy explícito en subrayar la prohibición del derecho a manifestación, solo admitía los principios de asociación y de reunión siempre que fuera en «locales cerrados» y sobre las huelgas ni siquiera se molestó en aclarar su legalidad. El problema religioso quedaba supeditado a la elaboración de un censo confesional entre los españoles y reconocía que, en caso de que dicha encuesta no arrojara una respuesta mayoritaria, España dejaría de tener una religión oficial. El proyecto de Campo Alange se completó con una serie de cláusulas que garantizaban un orden conservador y elitista. En la política nacional propugnaba por la renovación de los representantes políticos de las cámaras por tercios para evitar «temibles y periódicas conmociones»y, siguiendo la imagen de los Senados decimonónicos, añadía un número indeterminado de diputados de la Iglesia y de la Diputación de la Grandeza. Asimismo, para solucionar la tradicional debilidad de los gobiernos de la Restauración, reconocía la plena autonomía del monarca para nombrar el ejecutivo en la forma de un Consejo Superior de la Nación. Su plan se terminaba reforzando el poder de los funcionarios y técnicos del poder ejecutivo, militar y judicial, al dotarlos de «severos reglamentos»y eximirlos de toda influencia política.

Si la propuesta de Campo Alange encarna la vertiente más amateur de la política aristocrática y la de Eliseda una suerte de tentación fascista, la obra del vizconde de Eza atestigua en cambio un carácter más erudito. La trayectoria personal de Luis Marichalar y Monreal merece ser reseñada dado que unió todas las formas de capital económico, social y político que dispusieron las élites de la Restauración (65). Gracias a la cuidadosa conservación del antiguo patrimonio familiar, pero también debido a su matrimonio con Encarnación Bruguera, gozaba de una importante fortuna compuesta por fincas, propiedades urbanas y valores extranjeros (66). Eza representaba también el prototipo del notable del liberalismo: elegido diputado de forma ininterrumpida por Soria desde 1899 hasta 1923, fue ministro en varios gabinetes de la monarquía y uno de los miembros más importantes de la Asociación de Agricultores de España (67). Por último, Luis Marichalar destacó asimismo por su inquietud intelectual y por escribir una obra muy prolija en cuestiones de orden social y económico (68).

(65) CARASA Soto (1997): vol. II, 361-365

(66) Sus declaraciones de la renta de 1933 a 1935 en AHN, Fondos Contemporáneos Ministerio de Hacienda, Caja 7106.

(67) Pan-Montojo (2007): 91.

(68) CAMPo GarCía (1968) 
Con la llegada de la Segunda República, Eza renunció a permanecer en la primera línea política y tampoco hay constancia de que apoyara ni a los círculos de Acción Española ni a Renovación Española. Sin embargo, ello no impidió que siguiera las diversas propuestas corporativas del momento con visos a madurar su proyecto personal. Empezó en 1934 con una conferencia en el Ateneo Sevillano bajo el título La Corporación como estructura nueva del Estado, donde daba cuenta de la multitud de propuestas que emanaban tanto de las naciones de referencia (Gran Bretaña, Francia o Portugal) pero también de países menos conocidos para el público español (Austria o Rusia) (69). Para Eza todos estos experimentos resultaban sin duda prometedores, pero quedaban lejos del sueño de crear un sistema de corporaciones independientes del poder político existente y capaz de superar el enfrentamiento entre clases. Además, como señalaba en relación al caso español, la completa «indisciplina social» y la debilidad de las «clases directoras» que se manifestaba en aquellos años hacían imposible que floreciese el corporativismo en todo su esplendor (70).

Tras pasar la Guerra Civil recluido en su casa en Madrid, el vizconde de Eza continuó madurando su propuesta corporativa. En 1940 publicó una breve reivindicación de las élites, a la que ya antes me refería, y tres años más tarde presentó Piedras Miliarias, una colección de pequeños libros que referían a «los principios, fundamentos y postulados permanentes» necesarios para hacer «al hombre sano de espíritu y, por ende, prósperas a las sociedades» (71). A lo largo de sus páginas, el autor hacía gala de su enorme capacidad erudita -citando con enorme conocimiento las experiencias de Francia, Alemania o Portugal-, mostraba sus recelos al fortalecimiento del poder del Estado en la esfera económica y terminaba haciendo un alegato a favor de un orden corporativo de trabajadores, gerentes y capitalistas.

En 1945, unos pocos meses antes de morir, Eza publicó la obra que sintetizaba su ideario: La representación del país (72). Su propuesta corporativa descansaba sobre tres pilares básicos. En primer lugar, reivindicaba la primacía de los principios morales conservadores (autoridad, familia, propiedad y religión) por ser consustanciales a la naturaleza de los españoles y, en consecuencia, entendía que quedaban fuera de toda discusión. Después, como forma de luchar contra la creación de un Estado autoritario y omnímodo, abogaba por un sistema de corporaciones que agrupara de manera independiente a patronos y obreros. Para Eza resultaba vital que estas corporaciones no fueran un mero apéndice del sistema político, como daban a entender Eliseda y Campo Alange, y consideraba necesario salvaguardar su independencia hasta el punto de que cada corporación sería libre de fijar los salarios, producción y precios en sus
(69) EZA (1934)
(70) EZA (1934): 50-51.
(71) EZA (1943): 5.
(72) EZA (1945) 
respectivas ramas. En tercer lugar, en consonancia con su historial político, Luis Marichalar aclaraba que este sistema sólo era viable en una monarquía que tuviera como rey a Juan III. Reconociendo la legitimidad histórica de la Constitución de 1876, proponía cambiar las formas de representación política que habían caracterizado al sistema de la Restauración. El Congreso estaría dividido en tres tercios que coincidían con la propuesta de Campo Alange (obrero, productor y profesional), pero innovaba al suplantar el sufragio universal y el sistema de partidos por el principio de elección aleatoria (la insaculación) entre los miembros de la corporación que gozasen de domicilio y oficio conocidos. En la Cámara Alta persistirían los senadores por derecho propio (infantes, capitanes generales, almirantes, etc.) y se añadiría una representación puramente corporativa, incluyendo a la Diputación de la Grandeza, las Academias, la Iglesia, pero también cien representantes de propietarios y empresarios, otros tantos de obreros y 25 de entre todos los contribuyentes agrícolas. Eza completaba este diseño reconociendo al monarca la prerrogativa para nombrar al ejecutivo, eximía al gobierno del control parlamentario y declaraba la profesionalización política como una rémora caduca, pues cuando se terminasen los mandatos «cada cual reanuda su vida propia» (73). El proyecto adquiría de esta manera una dimensión utópica, por cuanto contemplaba el final de la política tal como se había conocido hasta ese momento y su sustitución por programas «económicos, sociales, educativos o morales» que debían ser dilucidados «por los organismos que están llamados a plantearlos y vivirlos».

No obstante, los proyectos de Eliseda, Campo Alange y Eza siempre tuvieron su punto más endeble cuando se confrontaban con la realidad. A pesar de que varios de los principios expuestos entraban en total contradicción con las esencias del Movimiento Nacional, ninguno de los tres presentó sus ideas en oposición al franquismo. Al contrario, todos guardaron un cómodo silencio con respecto al régimen y solo el conde de Campo Alange añadió una breve hoja de ruta al final de su manuscrito que atribuía a un gobierno militar la tutela de una paulatina transición hacia el régimen liberal-corporativo. Resulta igual de relevante que, cuando los intelectuales de la época reseñaron las obras de Eza y Eliseda en la Revista de Estudios Políticos, consideraron que los principios defendidos por ambos autores ya estaban recogidos en el diseño institucional del régimen de Franco y que solo había pequeñas diferencias que eran más bien una cuestión de matiz (74).

Al final, esta ambivalencia calculada entre defender la monarquía y convivir con un régimen autoritario no fue un rasgo exclusivo de la aristocracia sino del grueso de las fuerzas que apoyaban a Don Juan. Las bases de Estoril de 1946, donde los monárquicos plasmaron su programa de consenso, recogía varios elementos que podrían haber sido escritos por la pluma de un aristócrata: la religión católica, la unidad de España y la monarquía estarían fuera de toda

(73) EZA (1945): 165.

(74) Araujo-Costa (1945); RuIZ-GimÉNEZ (1945). 
discusión, el rey tendría una influencia decisiva para designar al gobierno y en las Cortes solo un tercio de sus miembros serían elegidos por sufragio directo, mientras que el resto se haría por parte de los ayuntamientos, agrupaciones culturales y corporaciones profesionales (75). No era la génesis de una oposición democrática al franquismo, como algunos historiadores han pretendido ver, sino el último canto de la política de los notables (76).

\section{CONCLUSIONES}

Desde la caída de la monarquía, la nobleza española manifestó un renovado interés en la vida política del país que le llevó a apoyar proyectos de naturaleza contrarrevolucionaria que a menudo le permitieron confluir con otros actores políticos. Junto con estas formas de movilización, las élites nobiliarias dieron muestras de compartir un proyecto de Estado que reconocía en la monarquía la mejor fórmula política, defendía los principios conservadores frente a los peligros del mundo moderno y reclamaba el dominio de las minorías selectas frente al empuje de las masas. Más tarde, durante los primeros años de posguerra, esta serie de imaginarios se plasmaron en proyectos corporativistas que pretendían restaurar la monarquía y alcanzar un arreglo institucional permanente que garantizase el orden político y la convivencia en armonía de todas las clases sociales. En retrospectiva, no es exagerado afirmar que las ideas defendidas por la aristocracia constituían un imaginario caduco incapaz de asumir muchos de los cambios provocados por el avance de la modernidad, en particular el final del turno entre los partidos liberal y conservador, la aparición de nuevas clases sociales y la creciente pujanza del Estado en la esfera económica. Esta intransigencia determinó de igual manera que la nobleza se viera cada vez más aislada, por lo que su ideario elitista basado en la defensa de la vieja monarquía liberal, la propiedad y el corporativismo estuviera abocado a quedar fuera de las corrientes políticas que iban a marcar los destinos del país a partir de 1931.

\section{BIBLIOGRAFÍA}

Alba, D. de. (1928). Relaciones de la nobleza con sus pueblos y plan de una codificación de las Ordenanzas dadas por los Señores a sus vasallos. Madrid: Tipografía de la Revista de Archivos.

(1943a). Discurso leído en el acto de su recepción por el Duque de Berwick y Alba sobre los Mecenazgos ilustres. Contestación del Duque de Maura. Madrid: Real Academia Española.

(75) CASALS (2005)

(76) El carácter democrático según ANSON (1994); TuSELL (1977): 252-253. 
- (1943b). Discurso pronunciado por el Duque de Alba en la toma de posesión del cargo de Decano Presidente. Madrid: E. Catalá.

Alcalá-Galiano, Á. (1928). Entre dos mundos: Seguido de un ensayo sobre la decadencia de Europa. Madrid: Espasa-Calpe.

- (1933). La caída de un trono (1931). Madrid: Compañía Ibero-Americana de Publicaciones.

- (1934). Renovación Española ante la sociedad. Madrid: Renovación Española.

Alfonso García, M. del C. (1998). Antonio de Hoyos y Vinent, una figura del decadentismo hispánico. Oviedo: Departamento de Filología Española.

Almansa Pérez, R. M. (2005). Familia, tierra y poder en la Córdoba de la Restauración : bases económicas, poder político y actuación social de algunos miembros de su élite. Córdoba: Universidad de Córdoba.

Anson, L. M. (1994). Don Juan. Barcelona: Plaza\&Janés Editores.

Araujo-Costa, L. (1945). Vizconde de Eza: La representación del país. Revista de Estudios Políticos, XIII(24), 321-326.

Artola Blanco, M. (2012). La transformación del mercado de alquiler de fincas urbanas en España (1920-1960). Biblio 3W, (988). Disponible en: http://www. ub. es/ geocrit/b3w-988. htm

- (2013). Los terratenientes frente al cambio agrario, 1940-1954. Historia Agraria (59), 125-158.

- (2014). La economía de la nobleza en el Madrid de 1930: ¿uno o varios modelos? En Grupo de estudio de Historia de la nobleza (ed.), La nobleza española, 1780-1930 (pp. 291-313). Madrid: RH+ Ediciones.

- (2015). El fin de la clase ociosa: de Romanones al estraperlo, 1900-1950. Madrid: Alianza Editorial.

Avilés Farré, J. (1996). Un Alba en Londres: la misión diplomática del XVII duque (1937-1945). Historia Contemporánea (15), 163-178.

Babiano Mora, J. (2012). El mundo del trabajo durante el franquismo. Algunos comentarios en relación con la historiografía. Ayer (88), 229-243.

Baranowski, S. (1995). The Sanctity of Rural Life: Nobility, Protestantism, and Nazism in Weimar Prussia. Oxford y Nueva York: Oxford University Press.

Barba Prieto, D. (2001). La democracia cristiana: 1936-1977. Madrid: Encuentro.

Bourdieu, P. (2007). La noblesse: capital social et capital symbolique. En D. Lancien y M. de Saint-Martin (eds.). Anciennes et nouvelles aristocraties, de 1880 à nos jours (pp. 385-397). París: Fondation Maison des sciences de l'homme.

Bravard, A. (2013). Le grand monde parisien: 1900-1939, la persistance du modèle aristocratique. Rennes: Presses universitaires de Rennes.

Bullón de Mendoza, A. (2000). Aristócratas muertos en la Guerra Civil española. Aportes, 15(44), 77-106.

Cabrera Acosta, M. Á. (2001). Historia, lenguaje y teoría de la sociedad. Madrid: Cátedra.

Cabrera, M. y Rey Reguillo, F. del (2002). El poder de los empresarios: política e intereses económicos en la España contemporánea (1875-2000). Madrid: Taurus. 
Camarasa, M. de (1931). Por qué ha salido de España S. M. el Rey: Abril de 1931. Madrid: Imp. de Antonio Marzo.

Campo García, F. (1968). El vizconde de Eza y la cooperación. Estudios Cooperativos, (16), 27-40.

Cannadine, D. (1999). The decline and fall of the British aristocracy. Nueva York: Vintage Books.

Carasa Soto, P. (ed.) (1997). Élites castellanas de la Restauración. Valladolid: Junta de Castilla y León, Consejería de Educación y Cultura.

Casals, X. (2005). Franco y los Borbones: la corona de España y sus pretendientes. Barcelona: Planeta.

Collado Seidel, C. (2007). Aristocracy, Fascism, and the Franco Dictatorship (19311945). En K. Urbach (ed.), European Aristocracies and the Radical Right, 19181939 (pp. 111-125). Oxford y Nueva York: Oxford University Press.

Conze, E. (2007). «Only a dictator can help us now»: aristocracy and the radical right in Germany. En K. Urbach (ed.), European Aristocracies and the Radical Right, 1918-1939 (pp. 129-147). Oxford y Nueva York: Oxford University Press.

D’Almeida, F. (2008). El pecado de los dioses: la alta sociedad y el nazismo. Madrid: Taurus.

Eliseda, M. de la (1945). Autoridad y libertad. Madrid: Escelicer.

Eza, V. de (1934). La Corporación como estructura nueva del Estado. Madrid: C. Bermejo.

- (1940). Vivero de selectócratas: (la función de las clases directoras en las sociedades modernas). Madrid: C. Bermejo.

- (1943). Piedras miliarias. Madrid: C. Bermejo.

(1945). La representación del país. Madrid: C. Bermejo Impresor.

Fernández Riquelme, S. (2008). Sociología, corporativismo y política social: las décadas del pensamiento corporativo en España: de Ramiro de Maeztu a Gonzalo Fernández de la Mora (1877-1977) [tesis doctoral]. Universidad de Murcia. Disponible en: https://digitum. um. es/xmlui/handle/10201/3276.

Franco Salgado-Araujo, F. (1976). Mis conversaciones privadas con Franco. Barcelona: Planeta.

Gil Pecharromán, J. (1994). Conservadores subversivos: la derecha autoritaria alfonsina (1913-1936). Madrid: EUDEMA.

Giménez Martínez, M. Á. (2012). Las Cortes españolas en el régimen de Franco: nacimiento, desarrollo y extinción de una cámara orgánica. Madrid: Congreso de los Diputados.

Glassheim, E. (2005). Noble nationalists: the transformation of the Bohemian aristocracy. Cambridge (Mass.): Harvard University Press.

Gómez-Navarro, J. L. , Rey Reguillo, F. del, Moreno Luzón, J. (1998). La élite parlamentaria entre 1914 y 1923. En M. Cabrera (dir.), Con luz y taquígrafos: el Parlamento en la Restauración (1913-1923) (pp. 103-142). Madrid: Taurus.

González Calleja, E. (2011). Contrarrevolucionarios: radicalización violenta de las derechas durante la Segunda República, 1931-1936. Madrid: Alianza Editorial. 
González Cuevas, P. C. (1993). Nobleza y contrarrevolución: el Centro de Acción Nobiliaria (aproximación nobiliaria a un grupo de élite). En J. Tusell, J. Gil Pecharromán, y F. Montero García (coord. ), Estudios sobre la derecha española contemporánea (pp. 225-267). Madrid: UNED.

- (1996). Habitus e ideología: El pensamiento político de Francisco Moreno y Herrera, Marqués de Eliseda. Cuadernos de Historia Contemporánea, (18), 83-114.

(1998). Acción española: teología política y nacionalismo autoritario en España (1913-1936). Madrid: Tecnos.

- (2003a). El rey y la corte. En J. Moreno Luzón (ed.), Alfonso XIII: un político en el trono (pp. 187-212). Madrid: Marcial Pons.

- (2003b). Maeztu: biografía de un nacionalista español. Madrid: Marcial Pons Historia.

- (2008). Aristocracia. En J. Fernández Sebastián y J. F. Fuentes (dirs.), Diccionario político y social del siglo Xx español (pp. 123-128). Madrid: Alianza Editorial.

Hernández Barral, J. M. (2014). Perpetuar la distinción: Grandes de España y decadencia social, 1914-1931. Madrid: Ediciones 19.

Macknight, E. C. (2012). Aristocratic Families in Republican France, 1870-1940. Manchester y Nueva York: Manchester University Press.

Malefakis, E. (1976). Reforma agraria y revolución campesina en la España del siglo xx. Barcelona: Ariel.

Malinowski, S. (2007). A Counter-Revolution d'Outre-tombe: Notes on the French Aristocracy and the Extreme Right during the Third Republic and the Vichy Regime. En K. Urbach (ed.), European Aristocracies and the Radical Right, 1918-1939 (pp. 15-33). Oxford; Nueva York: Oxford University Press.

Maura Gamazo, G. (1934). Recuerdos de mi vida. Madrid: M. Aguilar. (1952). La crisis de Europa. Madrid: Rialp.

Mina Apat, M. C. (2002). Aristocracia. En J. Fernández Sebastián \& J. F. Fuentes (dirs.), Diccionario político y social del siglo XIX español (pp. 95-103). Madrid: Alianza Editorial.

Moats, A. L. (1945). No passportfor Paris. Nueva York: Putnam.

Moreno Morrison, R. (1932). Guía nobiliaria de España: autorizada y controlada por la Excelentisima Diputación de la Grandeza de España. Madrid: Imprenta Suc. J. Sánchez de Ocaña y Cia.

Mosca, G. (1896). La clase política. México: Fondo de Cultura Económica.

Muret, M. (1939). Grandeur des élites. Fontenay aux Roses: Albin Michel.

Ortega y Gasset, J. (1930). La rebelión de las masas. Madrid: Revista de Occidente.

Pan-Montojo, J. L. (2007). La Asociación de Agricultores de España y la clase política, 1881-1942. Ayer, (66), 85-115.

Pareto, V. (1916). Forma y equilibrios sociales. Madrid: Revista de Occidente.

Phillips, G. D. (1979). The Diehards: Aristocratic Society and Politics in Edwardian England. Cambridge (Mass.): Harvard University Press.

Rivadabia, C. de (1935a). La Política. San Sebastián: Editorial Católica Guipuzcoa. (1935b). La Reforma Agraria. [s. 1. ]: Artes Gráficas Pasajes. 
Robledo, R. (2012). La expropiación agraria de la Segunda República (1931-1939). En S. de Dios, J. Infante, R. Robledo Hernández, y E. Torijano (coord. ), Historia de la propiedad: la expropiación (pp. 371-412). Salamanca: Universidad de Salamanca y Servicio de Estudios del Colegio de Registradores.

Ruiz-Giménez, J. (1945). Marqués de la Eliseda: Autoridad y libertad. Revista de Estudios Políticos, XIII(24), 300-317.

Saint Martin, M. de (1993). L'espace de la noblesse. París: Métailié.

Sánchez Marroyo, F. (2014). Riqueza y familia en la nobleza española del siglo XIX. Madrid: Ediciones 19.

San Juan de Piedras Albas, M. de (1945). Héroes y mártires de la aristocracia española: Julio 1936-Marzo 1939. Madrid: S. Aguirre.

Schmitter, P. C. (1974). Still the Century of Corporatism? The Review of Politics, 36(1), 85-131. Disponible en: http://dx. doi. org/10. 1017/S0034670500022178

Seidman, M. (2012). La victoria nacional: la eficacia contrarrevolucionaria en la Guerra Civil. Madrid: Alianza Editorial.

Sierra, M. (2010). Conceptos y discursos de representación. En M. Sierra, M. A. Peña, \& R. Zurita (eds.), Elegidos y elegibles. La representación parlamentaria en la cultura del liberalismo. Madrid: Marcial Pons.

Spengler, O. (1926). The Decline of the West: The Complete Edition. Nueva York: A. A. Knopf.

Stuart Hughes, H. (1952). Oswald Spengler: A Critical Estimate. Nueva York: Charles Scribner'ssons.

Tuñón de Lara, M. (1967). Historia y realidad del poder: el poder y las élites en el primer tercio de la España del siglo XX. Madrid: EDICUSA.

- (1981). Estudios sobre el siglo XIX español. Madrid: Siglo XXI de España.

Tusell, J. (1977). La oposición democrática al franquismo, 1939-1962. Barcelona: Planeta.

Urbach, K. (2007). Age of no extremes? The British aristocracy between the House of Lords and the Mosley Movement. En K. Urbach (ed.), European Aristocracies and the Radical Right, 1918-1939 (pp. 53-71). Oxford y Nueva York: Oxford University Press.

Urquijo, A. de. (1973). Cuando empuñamos las armas: la pequeña historia de una familia numerosa entre 1936 y 1942. Madrid: Moneda y Crédito.

Varela Ortega, J. (ed.). (2001). El poder de la influencia: Geografía del caciquismo en España (1875-1923). Madrid: Marcial Pons.

Vilallonga, J. L. de (2001). La cruda y tierna verdad. Barcelona: Debolsillo.

Villares, C. de los (1932). España en 1931. Madrid: Imp. Giralda.

Villavieja, M. de (1938). Life has been good; memoirs of the Marqués de Villavieja. Londres: Chatto\&Windus.

Wasson, E. A. (2006). Aristocracy and the modern world. Houndmills, Basingstoke, Hampshire; Nueva York: Palgrave Macmillan. 
